\title{
Study on the design of industrial control valves with manual drive
}

\author{
Andrei Pascariu* \\ "Gheorghe Asachi" Technical University, Iași, România
}

\begin{abstract}
The paper presents the main components and the operating mode of the manually operated control valves used in natural gas transport and distribution installations. Main parameters are specified: inlet-outlet pressure $(\mathrm{P})$, temperature $(\mathrm{T})$, flow rate $(\mathrm{Q})$, which are taken into considerations from the design phase and beyond. Noise is another parameter, in close liaison with the pressure and flow. As their value increases with both the inlet noise levels downstream of the valve is greater. By optimizing internal components, especially cages, noise can be limited below the maximum allowed by regulations. Also, there are presented control valve constructive types so that the optimal variant can be chose.
\end{abstract}

\section{Introduction}

Control valves are equipments which are used in natural gas transport and distribution installation for flow rate / outlet pressure control. The movement of piston modifies the flow area through the valve and the control of flow rate/ outlet pressure is made.

Are valves with valve plate, flanges and straight body. These are built on a cast carbon steel body; The size of the control valves can be from DN 25 up to DN 400 and nominal pressure from PN 16 up to PN 100.

Actions shall be taken so the pressure won't rise above the maximum allowable pressure (PS). For short periods it is allowed a pressure equal to $1,1 \mathrm{x}$ maximum allowable pressure (PS).

\section{Systemic analysis of manually operated control valves constructions and functioning}

The main components of a control valve are presented in Figure1.

The body 1 is the basic component parts to be assembled which constitute the control valve. Inside the gas flow direction change and gas expansion take place. At the bottom of the inspection cover 2 is mounted, which allows access to the seat 3 . This is a designated location by passing gas and to realize that closing and regulation of gas. The inside diameter is equal to the nominal diameter of the control valve (ex. $\varnothing_{\text {scaun }} 50 \mathrm{DN}=50 \mathrm{~mm}$ ). Effective adjustment is performed by the shutter member or piston 4 , which performs a linear movement equal to $1 / 4 * \mathrm{DN}$. The silencer 5 is designed to reduce the noise emitted by the

*Corresponding author: andrey_octavian@yahoo.com 
fluid flow through the valve and to strengthen the assembly formed with piston guide 6 . This serves to guide and center piston 4, the interior is fitted with sealing, through the sealing between the piston guide and piston the force generated by the pressure on the piston is cancelled. Linear movement of the piston 4 is caused by the rotation of the stem 7 . Connection part 8 is support element for stem guide 9 on the valve body 1. Handwheel 10 is the actuating system of the valve. Through the seal between the stem 7 and the guide stem 9 does not occur gas emissions in the atmosphere. This sealing can be done in several versions.

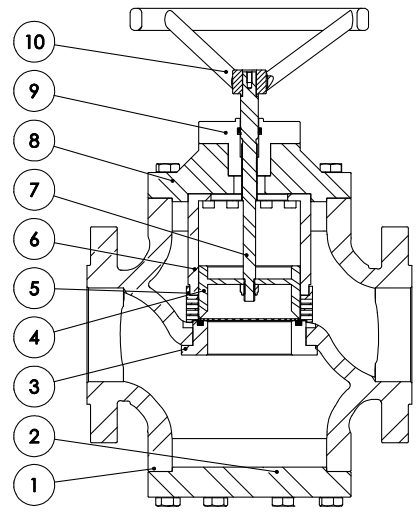

Fig .1. Manually operated control valve.

In Figure 2 are shown, the existing solutions of components that compose a control valve. Among these is proposed a new solution silencer slotted in one cage. Going through the scheme, may result in a control valve body with 2 port, with the captive O-ring seat, high pressure piston, slotted silencer and sealing the stem with two rings. For each component can develop a new improved version.

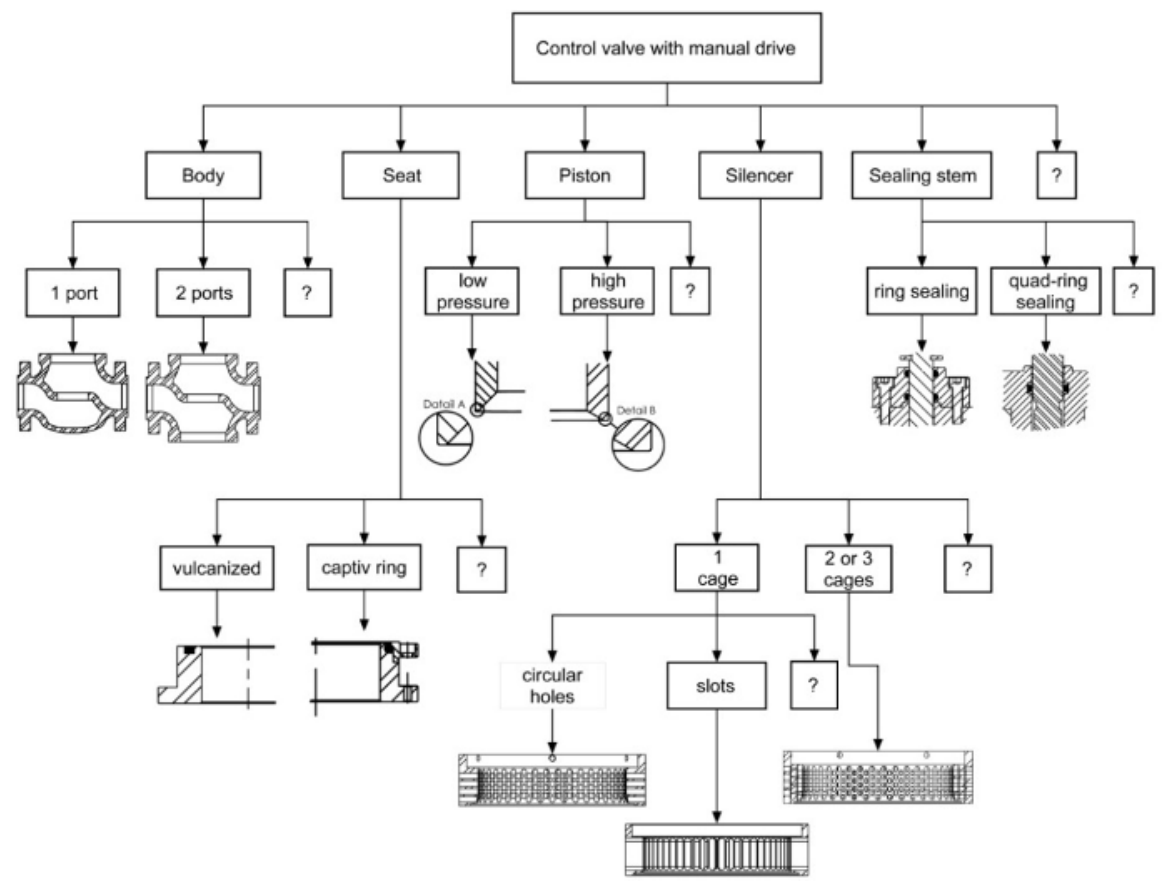

Fig. 2 Chart ideas with main components of control valves with manual drive. 
The functioning of the valve: the gas enters the valve through the inlet connection, passes through the seat and into the piston, (flow to open-FTO). The gas amount which will pass to the outlet connection varies depending on the distance of the piston from the seat (fig.3). Expansion is made when the gas passes through the space between the piston and seat. If the control valve is equipped with silencer expansion is made when the gas passes through the holes of the silencer.[1]

The piston movement compared to the seat is realized by the manual actuator (with screw). The piston stroke, from $0 \%$ to $100 \%$ is determined by multiplying the piston diameter with $0,25(0,25 \times \varnothing d$ piston $)$. In this way, the passing section area through seat is equal to the "cylinder" area generated by the piston movement from $0 \%$ to the $100 \%$ opening.

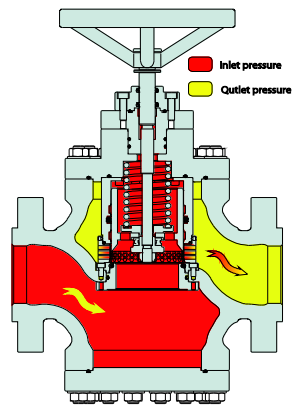

Fig. 3. Manually operated control valve. [1]

The main parameters of the gas at the valve inlet are: flow rate pressure and temperature

The control valve operating mode is determined by the three main parameters: input and output gas pressure $(\mathrm{P})$, mass flow rate $(\mathrm{Q})$ and temperature $(\mathrm{T})[2]$. The flow rate is the physical parameter which is measured in $\mathrm{m}^{3}$, which can be normal $(\mathrm{N})$ or standard $(\mathrm{S})$, per hour (h) or per day (d). The flow speed must not exceed, at outlet flange, $20 \mathrm{~m} / \mathrm{s}$.

The flow rate control is made also by pressure variation, for this reason we cannot have a low flow at high pressure (at control valve outlet).

\section{Analysis of the components}

Control valve bodies are manufactured by casting, from normative accepted materials (WCB vs LCC) [3], depending on minimum functioning temperature. Body can be made in two constructive types: with 1 and 2 ports.

The body with two ports (fig. 4.a) has the advantage that allows access to the underside of the seat, easy maintenance, it can be equipped with safety device, the actuator mechanism can be mounted on both ports. The disadvantage is that it requires inspection cover involving semiproduct processing and additional fasteners.

The advantage of body with 1 port (fig. 4.b) is that it has fewer parts, but has the disadvantage that cannot be equipped with safety device.

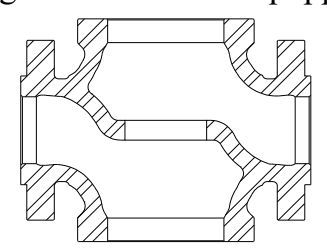

a)

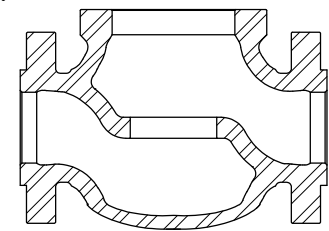

b)

Fig. 4. Control valve body: a) with 2 ports, b) with 1 port. 
Coupling connections are body parts and serve as connection to the sections and equipments from upstream and downstream. They can be manufactured in 2 constructive types:

- $\quad$ Standardized flanges PN or Class (RF, RTJ) (fig. 5.a);

- Weld ends (fig. 5.b);

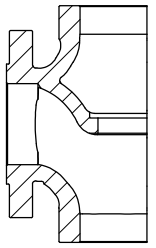

a)

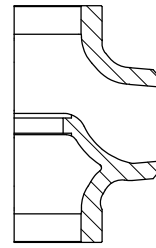

b)

Fig. 5. Control valve body: a) with flanges, b) with weld ends. [4]

The seat, at this valve type can be realized in 2 types, vulcanized (fig. 6.a) or captive ring (fig. 6.b). NBR or VITON ring are used with a 70 ShA or 90 ShA hardness. The rings with the hardness of $90 \mathrm{ShA}$ are used for valves working at pressure above $60 \mathrm{bar}$.

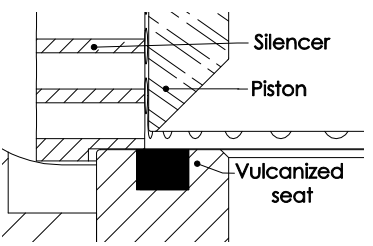

a)

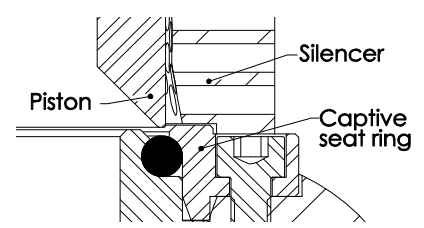

b)

Fig. 6. Seat variants: a) vulcanized, b) captive ring.

The silencer is an accessory which can be mounted on the valve if the noise level is high and above the limitation imposed by the normative. It can be manufactured from a single cage with circular holes (fig.7.a) or slots (fig.6.c), or by 2 or 3 cages assembled into each other with a deviation between the holes made in it (fig.6.b); in this way, the noise reducing capacity is increased.

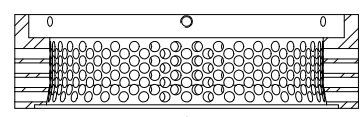

a)

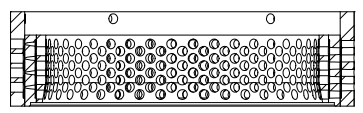

b)

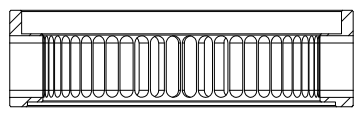

c)

Fig. 7. Versions silencer: a) with 1 port, circular holes; b) with 3 cages, circular holes; c) with 1 cage with slots.

The design of this style flow cage gives the added benefits of flexibility of size, pressure class, materials of construction, rangeability and attenuation [5].

The piston, by its movement, modifies the fluid flow area. Depending of closing pressure value, the form of the piston sealing part is sharp (fig.8.a) or flat (fig.8.b).

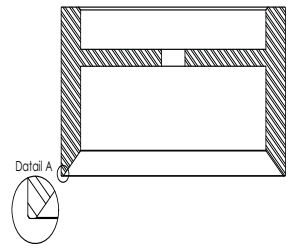

Fig. 8. a. Low pressure piston.

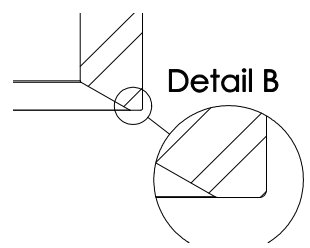

Fig. 8. b. High pressure piston. 
The stem guide is placed at the upper side of the valve and helps the stem to perform the linear movement and with it, the piston. This component also seals the stem. The stem sealing can be made by several means available on market. One way is sealing with two rings, the first one realize the sealing and the second one serves as a reserve if the first one brakes (fig.8.a).

Other mode of sealing is with quad-ring (fig.8.b). The manufacturers recommend using quad-rings for dynamic sealing. The stem performs two movements, rotation and translation, and the sealing is considered dynamic. For the surfaces in contact with sealing elements are prescribed special machining conditions. In normative SR EN 15848 Measurement, test and qualification procedures for fugitive emissions the stem emissions, methods and means of determination for these oversights are regulated [6].

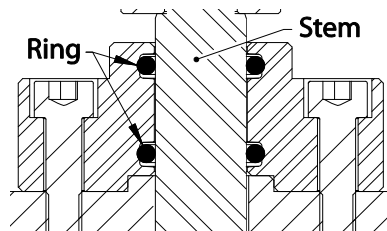

Fig. 8. a. Ring sealing. [1]

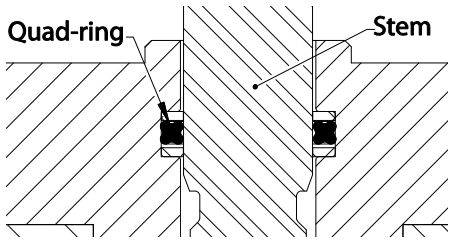

Fig. 8. b. Quad-ring sealing.

Schematically in the Figure 9 it is presented the detector probe (sniffing) method, allows the measurement of the local emission of the stem sealing system . The measured concentration is expressed in parts per million volume $(1 \mathrm{ppmv}=1 \mathrm{mil} \mathrm{m} 3=1 \mathrm{~cm} 31 \mathrm{~m} 3)$.

This procedure is intended to locate and classify leaks only, and is not used as a direct measure of mass emission rates from individual sources [6].

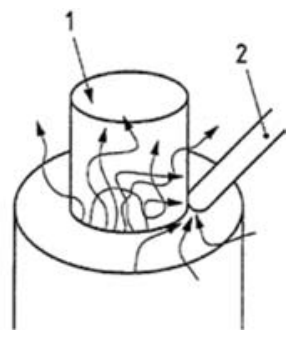

Fig. 9 Local measurement sniffing. [6]

In the next figure (Figure 10) constructive variants of the control valve components are presented. From this image, depending on the parameters, you can define the constructive solution of such equipment.

\section{Conclusions}

This paper shows the main components of the control valve manually operated. Each component can be designed in many variants. To achieve a control valve assembly pairs are chosen variations or part that would best fit in terms of functionality and cost, application for which is being executed.

The new elements presented in this paper are stem sealing with quad-ring and slotted silencer.

For optimal solution of low pressure control valve is composed of body with two ports, with vulcanized seat mounted, sharp active piston edge, slotted silencer and the stem sealing quad-ring. 


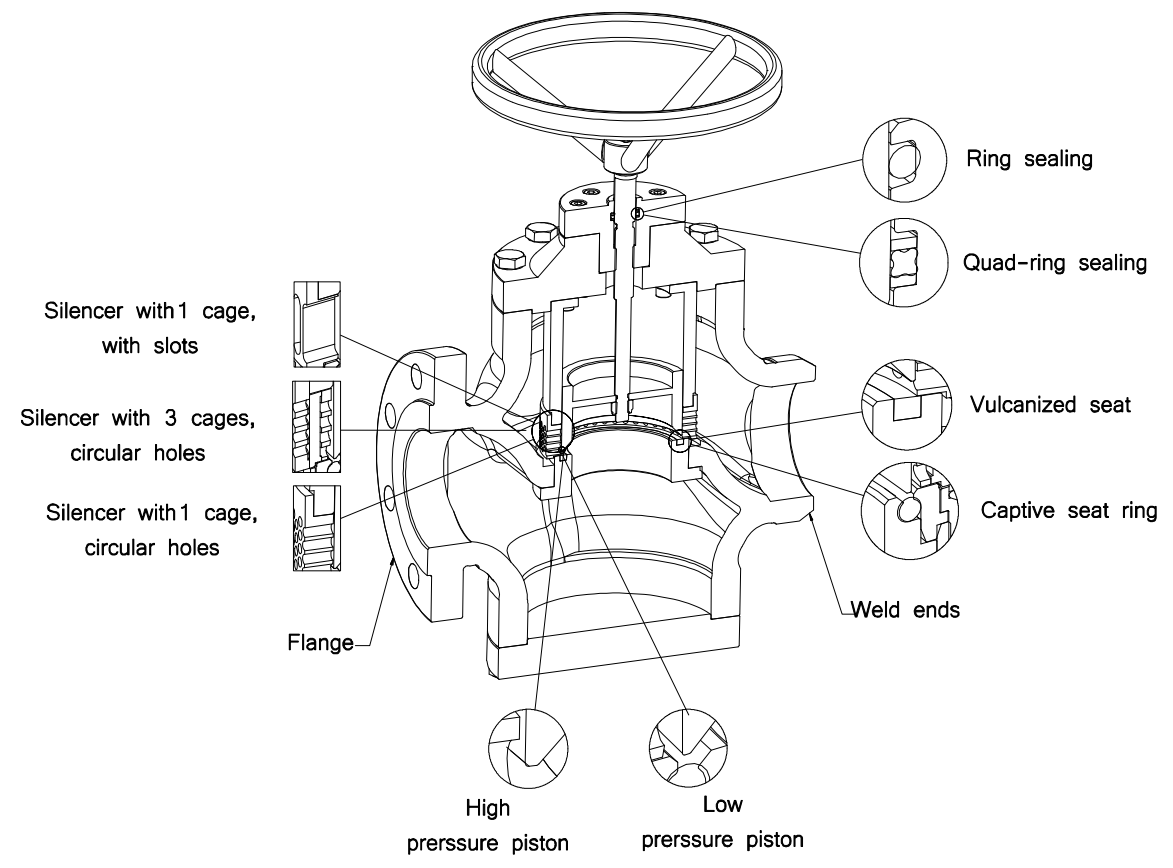

Fig. 10. Constructive solutions for the components of manually operated control valve.

With control valve manually operated with working a high pressure, on the body 2 port is recommended to mount the seat ring captive, flat active edge piston (not to damage the Oring due to force high press), silencer with 3 cages and circular holes (for low noise) and the stem sealing quad-ring.

\section{References}

1. TOTALGAZ INDUSTRIE, Techical manual (in Romanian), MT_RR 931_M, nr. 1181

2. M.V. Balyaba, M. A. Ermilov, A. N. Kryuchkov, Procedia Engineering, 176, 577 (2017)

3. SR EN 334+A1:2009, Gas pressure regulators for inlet pressures up to 100 bar

4. SR EN 60534, Industrial process control valves

5. http://www.documentation.emersonprocess.com/groups/public/documents/articles_art iclesreprints/ce control vlvs evolution desi.pdf

6. SR EN 15848, Measurement, test and qualification procedures for fugitive emissions 